\title{
INFLUENCE OF NOTCH ORIENTATION ON DUCTILE TEARING IN SENT SPECIMENS
}

\author{
R. Turtelboom ${ }^{1}$, P. Vandenbroucke ${ }^{1}$, K. Van Minnebruggen ${ }^{1}$, \\ S. Hertelé ${ }^{1}$, M. Verstraete ${ }^{1}$ and W. De Waele ${ }^{1}$ \\ ${ }^{1}$ Ghent University, Laboratory Soete, Belgium
}

\begin{abstract}
There is a growing interest for the use of spiral welded pipes in strain based design related applications. Since the influence of the spiral weld on the plastic behaviour of the pipe is not yet fully understood, further research on this topic is required. An important aspect of this plastic behaviour is the effect of mixed mode loading on weld defects located in the helical weld. This paper elaborates on the first experimental trials to evaluate ductile tearing by means of single edge notched tensile specimen (SENT) testing with slanted notches. Tests were performed on two SENT specimens, one with a slanted notch and another with a straight notch in order to investigate the influence of mixed mode loading. The crack mouth opening displacement and crack extension were determined experimentally by means of digital image correlation and potential drop measurements respectively. The crack extension and the potential drop measurements were related by means of finite element simulations.
\end{abstract}

Keywords: Spiral Linepipe; Strain Based Design; SENT specimen; Finite Element Analysis

\section{INTRODUCTION}

Due to the ever increasing demand for energy, more and more oil and gas pipelines are being installed to extract fossil fuels from harsh natural environments. These pipelines might have to withstand large plastic deformation as a result of for example discontinuous permafrost or seismic activity [1]. Consequently, the pipe axial straining capacity becomes equally important as the pipe hoop strength necessary for pressure containment. To take this into account, a strain based design approach should be applied. Such a design limits the allowable imposed axial strain to a fraction of the strain capacity. At the moment, strain based design for spiral welded pipes is not as well documented as is the case for UOE pipes. Due to the spiral weld and different anisotropic material response, the behaviour of spiral welded pipes will differ from that of UOE pipes. The use of spiral welded pipes could potentially lead to a project cost reduction of $5-15 \%$ compared to UOE pipes, which makes them attractive for industrial use. [2-4]. Studies have shown that, in comparison to UOE pipes, spiral pipes can have equivalent or better properties regarding to bending [5], plastic collapse [6], bursting [7], ductile tearing [8] or buckling resistance [4, 9]. Also, it has been shown that the fatigue resistance and fracture arrest properties are at least equivalent to those of UOE pipes [10,11].

This work is situated within the framework of a research project focusing on the tensile strain capacity of spirally welded pipes with seam weld defects. The aim of this work is to develop a combined numericalexperimental methodology to evaluate the tearing resistance of notches having a slanted orientation with respect to the loading direction. This leads to mixed mode loading condition as discussed in section 2. Because it is known that the constraint of Single Edge Notch Tension (SENT) specimens resembles this of full pipes [12, 13], this geometry has been selected as key element of the methodology. Specimen dimensions, notch orientation and advanced instrumentation are discussed in section 3. Finite element analyses discussed in section 4 are used to relate potential drop measurements to crack extension. Discussion of these results is elaborated in section 5 . 


\section{MIXED MODE LOADING}

When a crack occurs in a structure or weld, it can be subjected to different loading conditions as illustrated in Figure 1. In Mode I a tensile stress opens the crack while in modes II and III the crack is loaded by a shear stress.

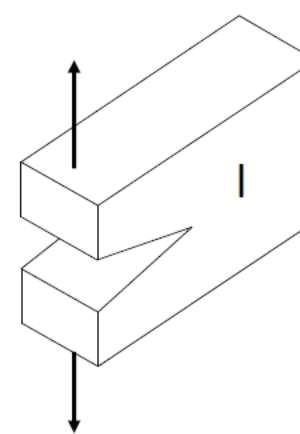

Mode I

Opening Mode

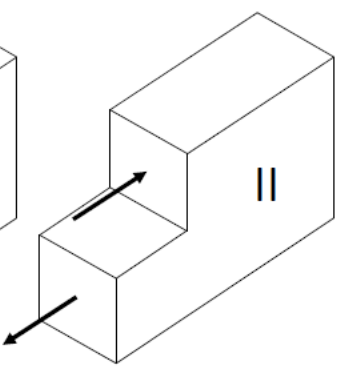

Mode II

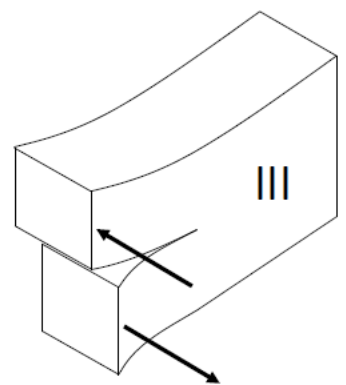

Mode III

Figure 1. Loading conditions

When a pipeline is subjected to axial tension, the girth welds joining different pipe sections are primarily loaded in mode I. In the case of spirally welded pipes, the seam weld is at an angle relative to the axial direction of the pipe $\left(90^{\circ}-\alpha\right)$. When the pipe is loaded in this direction due to an axial displacement, flaws in the seam weld will be subject to mixed mode loading, see Figure 2. Mode I will result in opening of the crack faces while mode III will cause a sliding motion of the crack faces along the length of the crack.

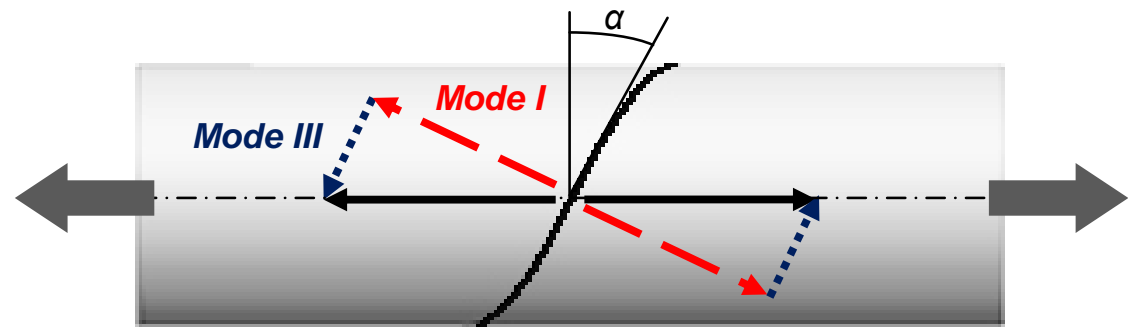

Figure 2. Mixed mode loading in spirally welded pipes

The components of mode I and III vary with the seam weld angle $\alpha$ and with internal pressure. It is obvious that when the seam weld angle increases, the mode III component will also increase. The internal pressure however, shall primarily increase the mode I component [14]. The main limitation in the case of mixed mode loading is the lack of standardized testing procedures. Research in this area is still at the development stage and no fracture criteria have been well-accepted. The total relative displacement of a pair of nodes at a fixed distance to the flaw tip on the undeformed crack front can be used to evaluate the mixed mode fracture toughness, see Figure 3 [15]. This total crack opening displacement (COD) consists of a mode I component $\left(\mathrm{COD}_{\mathrm{I}}\right)$ and a mode III component $\left(\mathrm{COD}_{\mathrm{III}}\right)$ [14]. The relationship between the total $\mathrm{COD}$ and its components is given in the following equation:

$$
C O D^{2}=C O D_{\mathrm{I}}^{2}+C O D_{\mathrm{III}}^{2}
$$

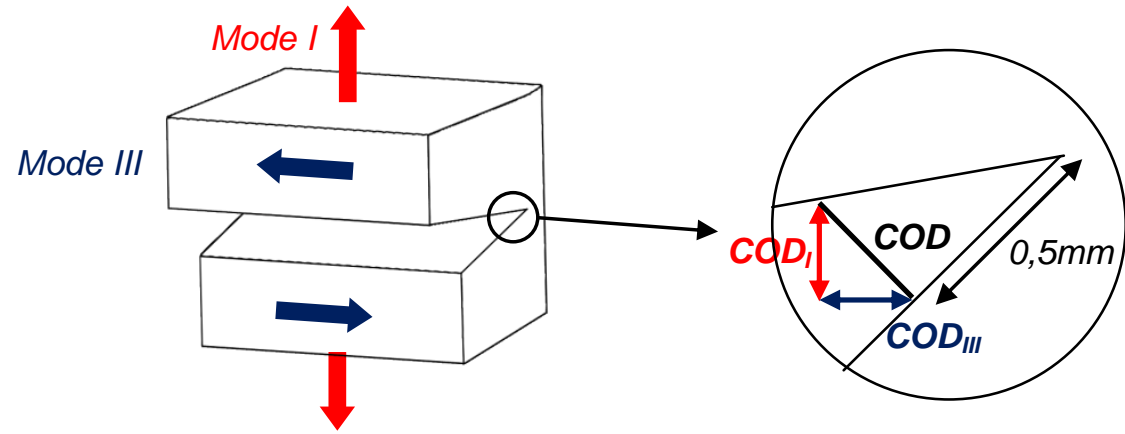

Figure 3. COD in mixed mode loading 
To evaluate the tearing behaviour in mixed mode loading, two SENT specimens were tested. One had a straight notch and the other a slanted notch of 31 degrees with respect to the transverse direction. The SENT specimens are illustrated in Figure 4. The total length $(L)$ of both specimens was approximately 255 $\mathrm{mm}$, while the daylight length $\left(L^{\prime}=\right.$ length of the specimen between the clamps) was $140 \mathrm{~mm}$. Both specimens had a width $(W)$ of $14 \mathrm{~mm}$ and height $(H)$ of $14 \mathrm{~mm}$. Electric current pins were attached to the specimen at a distance of $120 \mathrm{~mm}$ from each other. Holes were drilled at both sides of the notch, $9 \mathrm{~mm}$ apart and at an equal distance from the notch to be able to measure the potential drop over the crack. Holes for a reference potential drop measurement were drilled $14 \mathrm{~mm}$ apart, with the center at approximately $35 \mathrm{~mm}$ from the notch. The investigated material is an API X70 grade steel, which corresponds to a minimum tensile strength of $565 \mathrm{MPa}$ and a minimum yield strength of $483 \mathrm{MPa}$ [16]. The initial crack depth $\left(a_{0}\right)$ of both specimens was $7 \mathrm{~mm}$. The specimens are clamped and loaded in tension using displacement control. During the test, potential drop measurements were carried out in order to evaluate the evolution of the crack depth. Furthermore, DIC (Digital Image Correlation) was used to measure the crack opening displacement (COD). After the test, the specimens were cooled in liquid air and broken in a brittle way, which allowed the amount of ductile crack extension that occurred during the test to be measured.

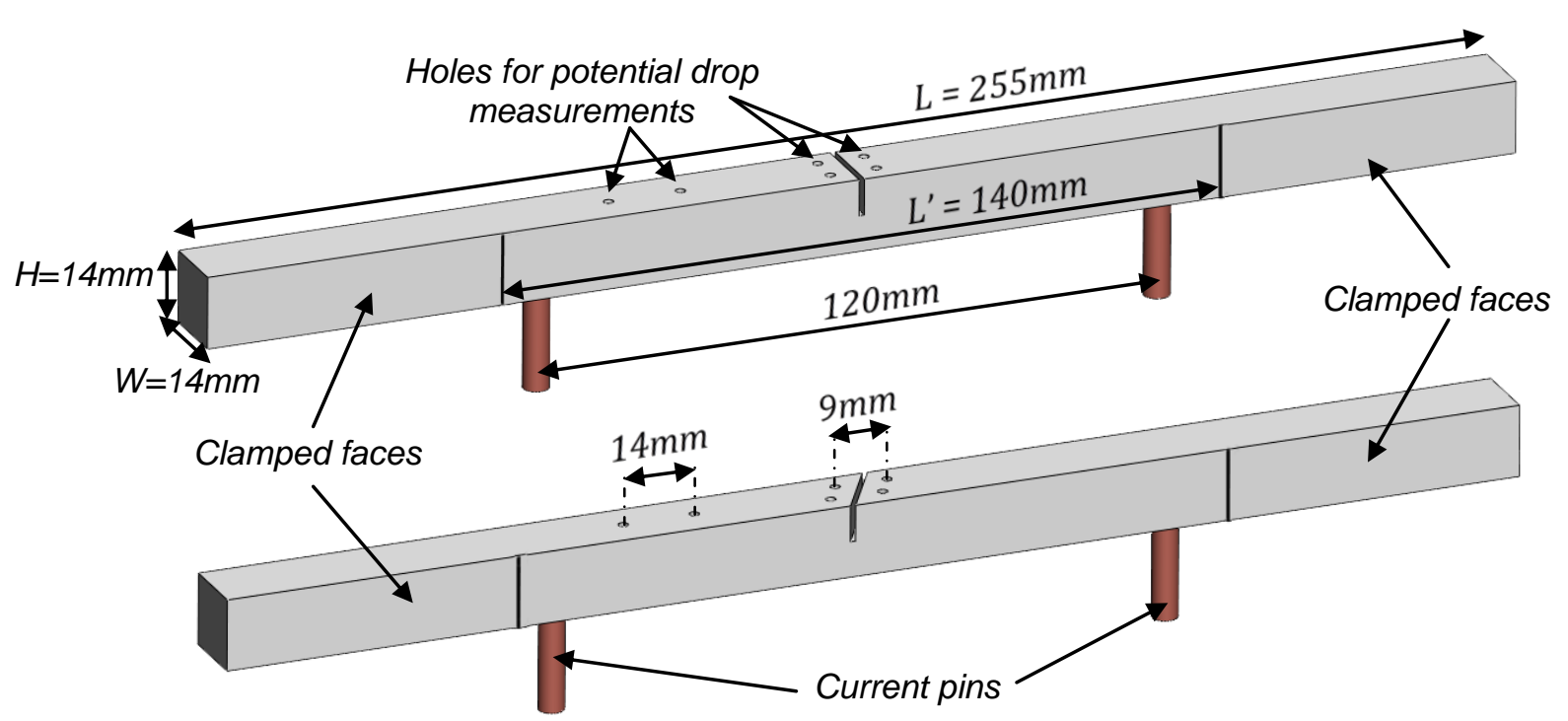

Figure 4. SENT specimens: straight notch (upper) and slanted notch (lower)

\subsection{Potential Drop method (PD)}

The direct current potential drop method is based on the electrical conductivity of a metal and can be used to determine the crack depth in SENT specimens [17]. Ohm's law states that the potential drop is linear related to the current flowing through a specimen and the resistance of (a part of) this specimen. During the test, the crack tip first starts to blunt, which is associated with a linear increase of the PD caused by the change in conductivity due to plastic deformation. Once crack initiation has occurred, the PD will increase more than linear. This is because when the crack grows, the net section of the specimen at the crack decreases, resulting in a higher resistance. Thus, when a constant current passes through the specimen, the potential drop across the crack can be related to the crack depth. For both tests, an electrical current of $25 \mathrm{~A}$ was introduced.

The potential drop measurements for both specimens are shown in Figure 5. The potential drop across the notch (PD notch) and at a reference section at approximately $35 \mathrm{~mm}$ from the notch (PD reference) were measured. The reference measurement was carried out to be able to filter out any unwanted influences that are not related to the crack growth (e.g. temperature effects, non-constant current leak paths). Furthermore, by combining both measurements a normalized potential drop can be obtained (Normalized), this results in an independency of conductivity of the used material. The COD value used in the graph of the specimen with a slanted notch was obtained by combining both COD modes as explained in section 2. 

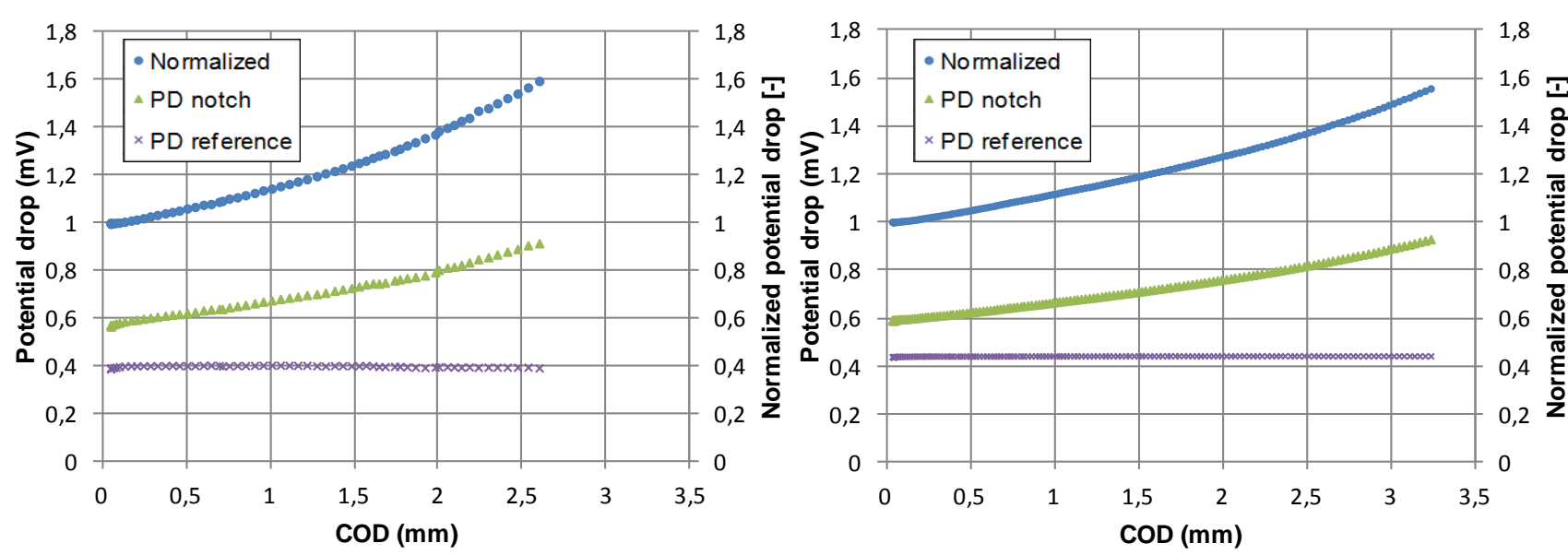

Figure 5. Potential drop measurements for straight notch (left) and slanted notch (right)

As can be seen in Figure 5, at the end of the tests, the potential drop over the crack has increased with $59 \%$ for the specimen with straight notch and $56 \%$ for the specimen with slanted notch.

To quantitatively determine the crack extension during the test, finite element analyses are used. The potential drop measurements are simulated for different crack depths. By relating the simulated potential drop values with the measured potential drops, the crack depth and by extension the crack growth can be determined. This is further discussed in section 4.

\subsection{Digital Image Correlation (DIC)}

The DIC method is based on a three-dimensional correlation of digital images from two different cameras that take images at specified load intervals. By processing images of the specimen in deformed and undeformed conditions, the deformation field at the specimen surface can be determined. In this work, the DIC method will be used to evaluate the relative displacement of a pair of nodes at the crack mouth and subsequently, to calculate the ductile crack opening $\left(C O D_{I}\right.$ and $\left.C O D_{\text {III }}\right)$ using trigonometry based on the angle of the crack.

In order to relate the DIC-displacements with COD values, displacements were measured at different heights. By applying a speckle pattern on blades with different thickness on the top surface of the specimen, displacements could be measured at different heights. To calculate the COD, the displacement of a pair of nodes at a height of $2 \mathrm{~mm}$ and $8 \mathrm{~mm}$ from the top surface of the specimen were used.

The COD of both specimens is plotted as a function of the applied force in Figure 6.
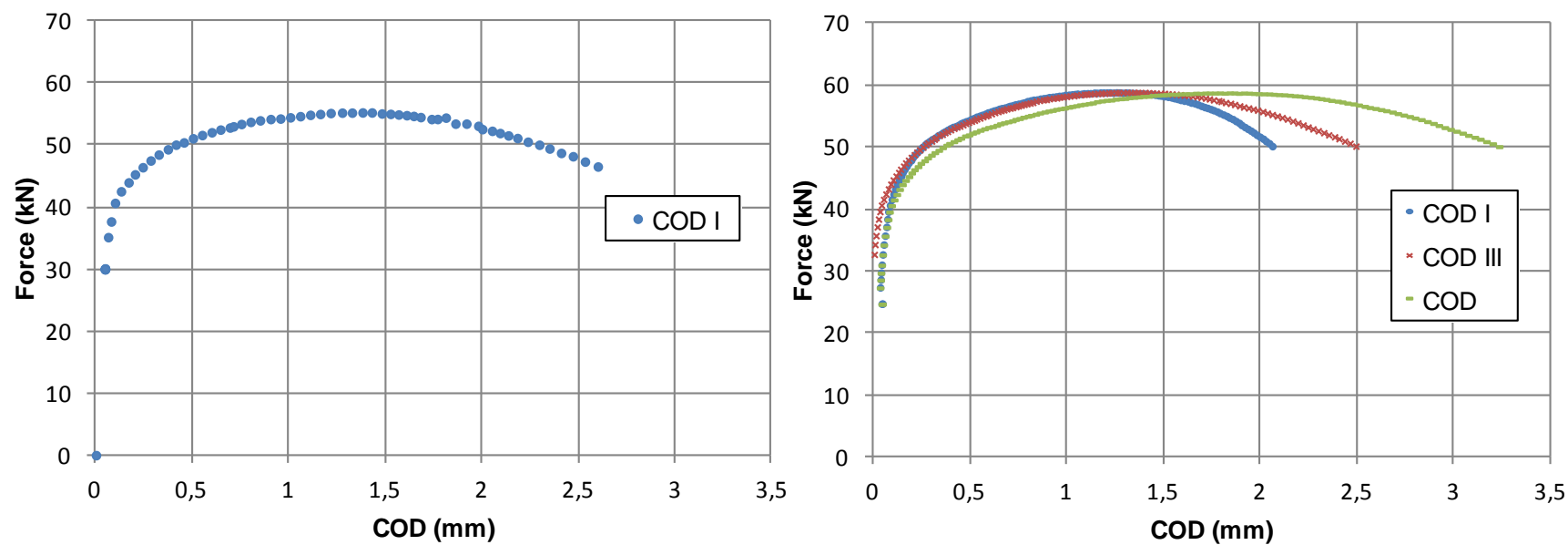

Figure 6. Measured COD values for straight notch (left) and slanted notch (right) 
For the slanted notch a significant mode III component can be discerned. This is also obvious by means of visual inspection of the specimens after testing (Figure 7). Further it can be seen on Figure 6 that for a slanted notch of $31^{\circ}$ the COD III component is even larger than the COD I component (COD I =2,06 mm and $\mathrm{COD} \mathrm{III}=2,49 \mathrm{~mm}$ at the end of the test)
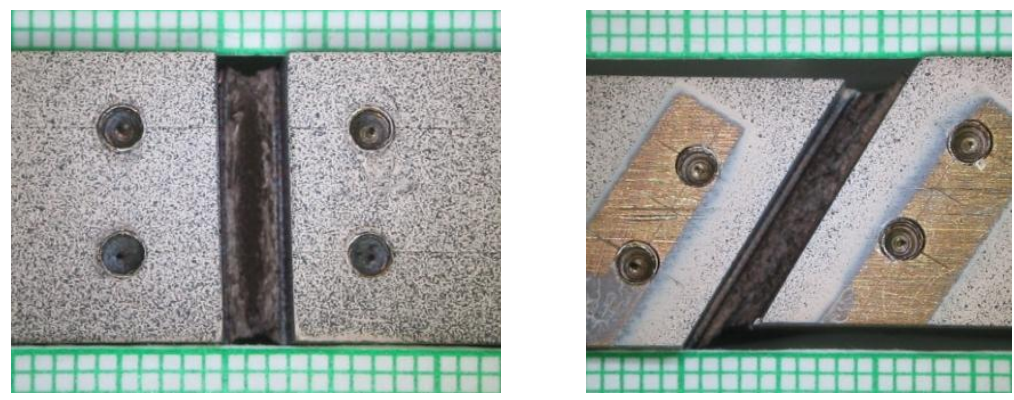

Figure 7. Top view on SENT specimens after testing (left: straight notch, right: slanted notch)

\subsection{Tunneling effect}

Both specimens were broken in a brittle way in order to evaluate the final crack extension by means of the nine points method. The crack lengths of the broken specimen are measured at nine equally spaced locations (Figure 8). Afterwards, an averaged crack depth is determined using the following equation:

$$
a=\frac{1}{8}\left[\frac{a_{1}+a_{9}}{2}+\sum_{i=2}^{8} a_{i}\right]
$$
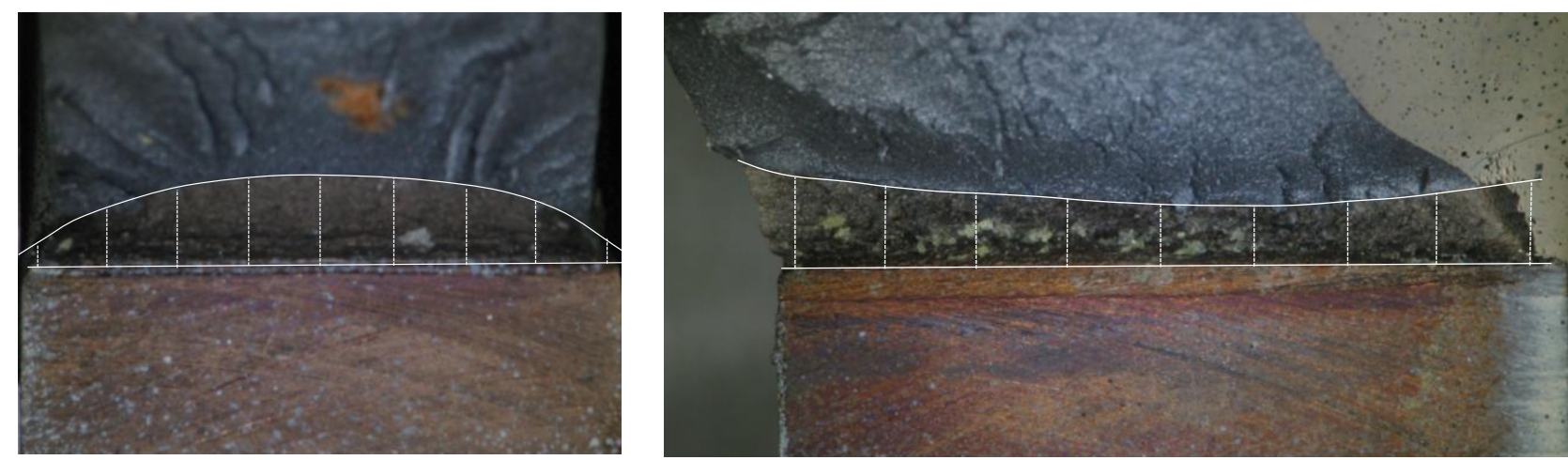

Figure 8. Determining crack depth using the nine points method (left: straight notch, right: slanted notch)

As can be seen on Figure 8, the ductile crack front of the straight notched specimen is arched. This effect is called "tunnelling". This is also evident from the large standard deviation of the measured crack depths $0,55 \mathrm{~mm}$ obtained from the nine points method. This tunneling effect is a consequence of the transition from a triaxial stress state at the center of the specimen to a biaxial plane stress state at the surface [18].For the specimen with slanted notch it can be seen that the crack front is concave instead of convex. The standard deviation obtained for this measurement is $0,20 \mathrm{~mm}$. The results for the two specimens are shown in Table 1.

Table 1: Measured ductile crack extension by means of nine point method.

\begin{tabular}{|l|c|c|c|c|c|c|c|c|c|c|c|c|}
\hline$[\mathrm{mm}]$ & $\mathrm{a}_{1}$ & $\mathrm{a}_{2}$ & $\mathrm{a}_{3}$ & $\mathrm{a}_{4}$ & $\mathrm{a}_{5}$ & $\mathrm{a}_{6}$ & $\mathrm{a}_{7}$ & $\mathrm{a}_{8}$ & $\mathrm{a}_{9}$ & $\mathrm{a}$ & AVG & STD \\
\hline $\begin{array}{l}\text { Straight } \\
\text { Notch }\end{array}$ & 0,48 & 1,40 & 1,78 & 1,95 & 1,97 & 1,91 & 1,71 & 1,22 & 0,57 & 1,56 & 1,44 & 0,55 \\
\hline $\begin{array}{l}\text { Slanted } \\
\text { Notch }\end{array}$ & 1.74 & 1.59 & 1.45 & 1.31 & 1.18 & 1,16 & 1,24 & 1,38 & 1,58 & 1,37 & 1,40 & 0,20 \\
\hline
\end{tabular}


Finite element analyses are carried out to simulate the electrical potential (EPOT, Volts) variation along the specimen (Figure 9). This way, the potential drop can be calculated for different crack depths and compared to the experimentally determined potential drops, using the mapping approach.

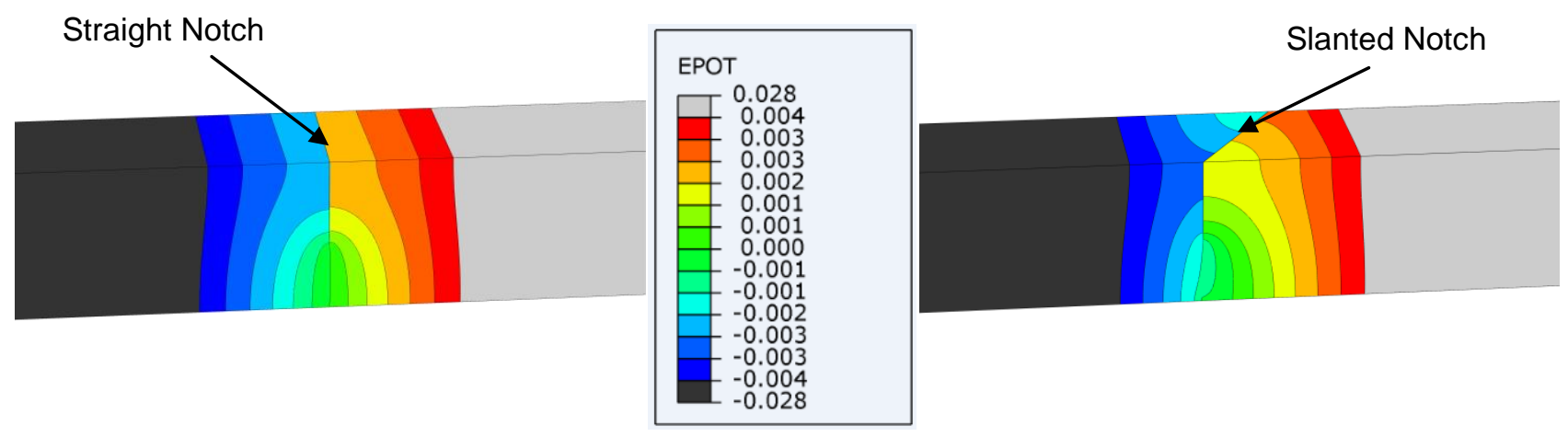

Figure 9. Simulated potential variation (left: straight notch, right: slanted notch)

As can be seen in the case of a slanted notch, the potential is not uniformly distributed through the width of the specimen at the position of the crack mouth. This can lead to significant effects in the measured potential drop as the exact position of the measurement pins is very influential on the measured potential drop. The potential becomes more homogenous in width direction at a certain distance of the crack. Consequently, the measurement pins should be placed in this homogenous region in order to reduce the error on the measured potential drop. In order to evaluate the proper position for the pins in the case of a SENT specimen with a slanted notch of $31^{\circ}$, the standard deviation of the mean potential through the width (at the surface of the specimen) is plotted as a function of the distance from the crack (for a crack depth of $8 \mathrm{~mm}$ ), as shown in Figure 10.

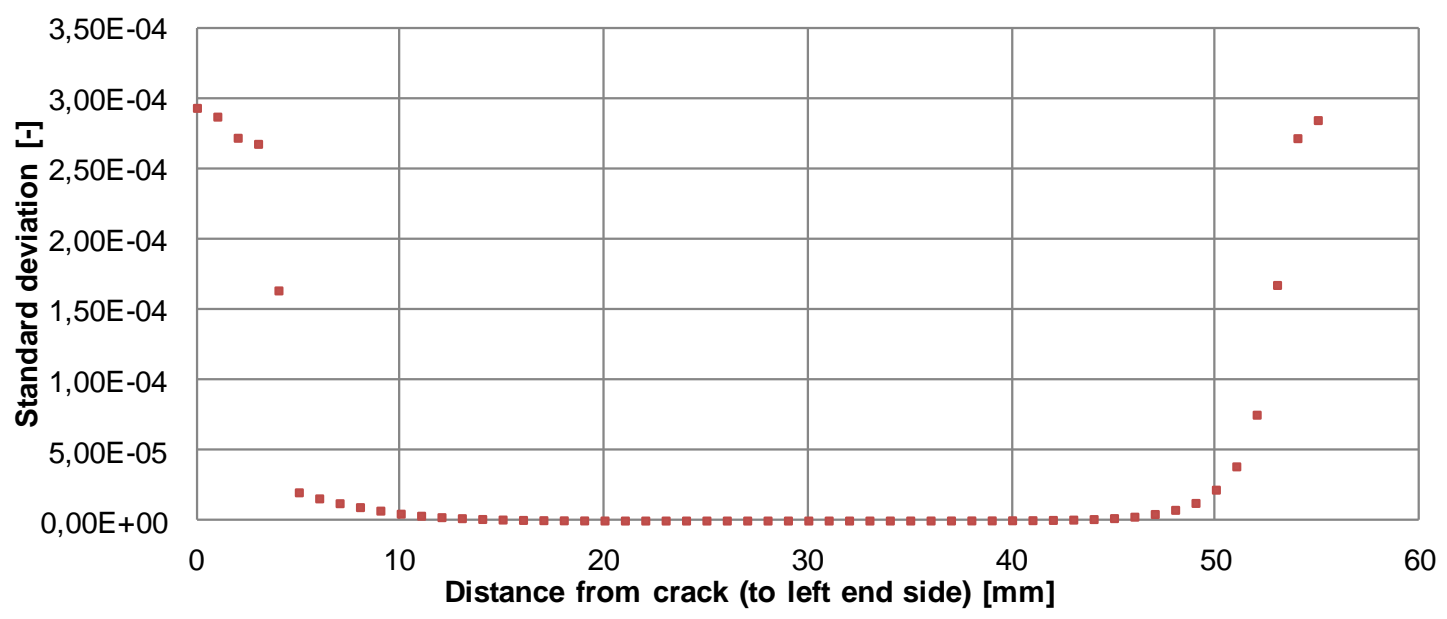

Figure 10. Average potential and standard deviation as a function of distance from the slanted notch

The peak in standard deviation at a distance beyond $50 \mathrm{~mm}$ from the crack is caused by the influence of the current pin. It can be determined that the standard deviation rapidly decreases when the pins are placed further from the crack. For a distance of $10 \mathrm{~mm}$, the standard deviation remains constant at a value of about zero. Consequently, the potential drop measurements should be more accurate when the measurement pins are at a distance of $10 \mathrm{~mm}$ or more from the crack. In the experiments, a distance of 4.5 $\mathrm{mm}$ is used. This results in a standard deviation of $<10^{-4}$.

The finite element analyses allow to derive a relation between (normalized) potential drop and crack depth. After calibration of this model, experimentally determined normalized potential drop can be related to crack extension. The calibration was done so that the ductile crack extension calculated from the finite element simulation matches the measured finale ductile crack extension. 


\section{DISCUSSION}

Combining the potential drop and DIC measurements allows to plot the COD as a function of crack extension. This is shown in Figure 11. For the slanted notch, the $C^{2} D_{1}$ en $C O D_{I I I}$ components were combined using equation (1).

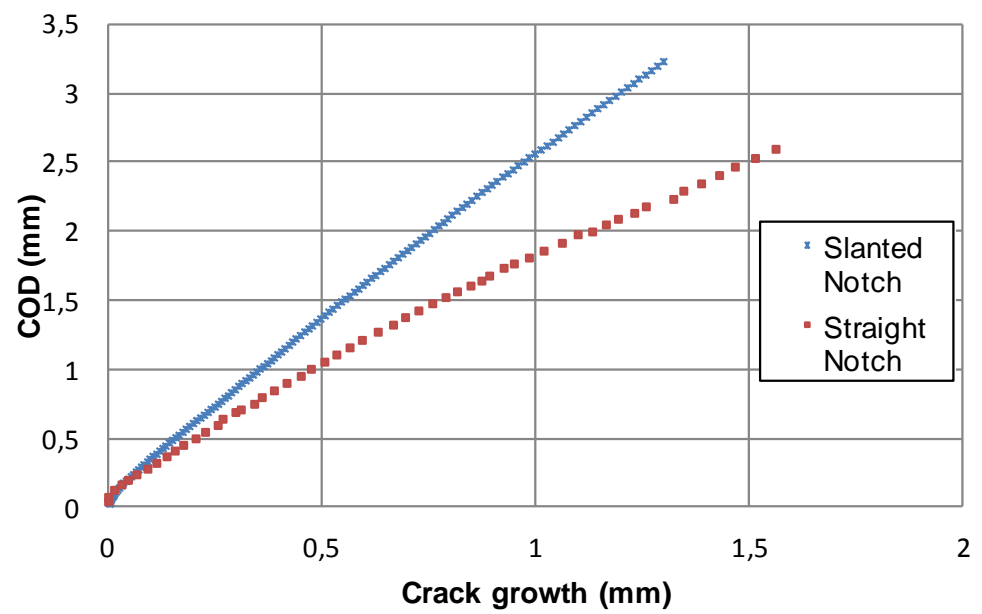

Figure 11. Crack growth (left: straight notch, right: slanted notch)

The final ductile crack growth measured with the nine points method is $1,56 \mathrm{~mm}$ for the specimen with the straight notch and $1.37 \mathrm{~mm}$ for the specimen with the slanted notch. As can be seen in Figure 11, the crack growth for a given COD value is larger for the straight notch than in the case of a slanted notch. This illustrates that a mode I loading will have a different influence on the tearing behaviour than a mode III loading. To further investigate this difference, both COD modes of the specimen with slanted notch are plotted as a function of the crack growth in Figure 12.

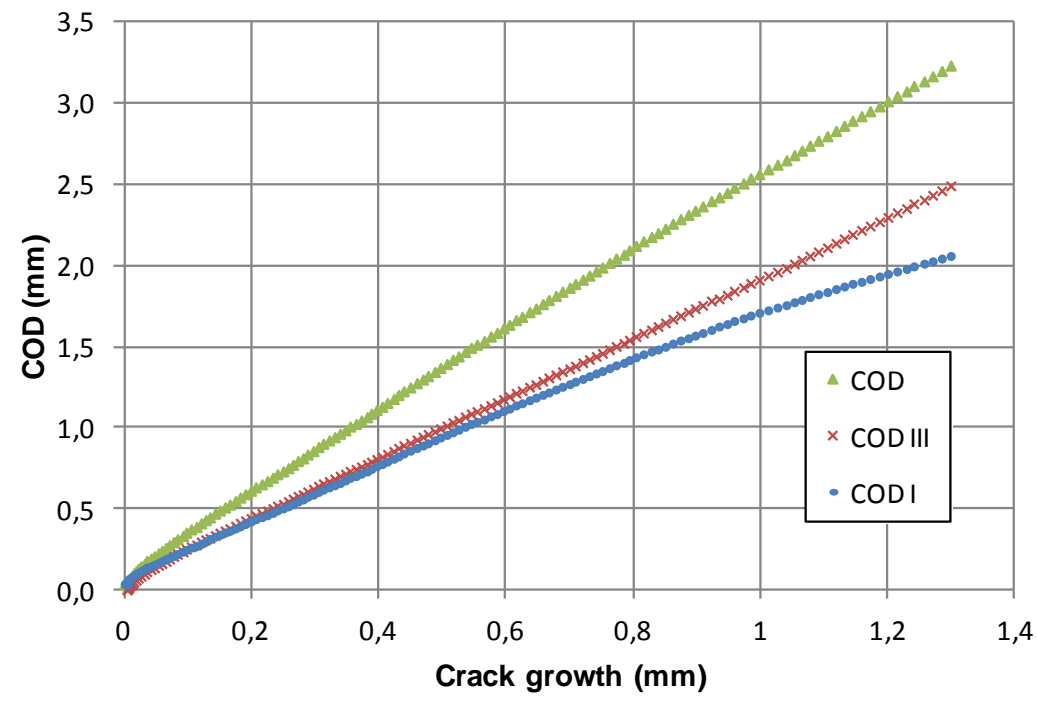

Figure 12. Crack growth for both COD modes in SENT specimen with slanted notch

The evolution of the $C O D_{1}$ in relation to the crack growth is qualitatively similar to that of the case with pure mode I loading (e.g. specimen with a straight notch). There is a difference however in the quantitative crack growth for a given $C O D$, value, which is caused by the added effect of the mode III loading. The evolution of the crack growth in relation to the $C O D_{\text {III }}$ values is more linear as compared to that of $C O D_{\text {I. }}$. The reason for this and whether this is also the case for slanted notches under different angles is subject of further investigation. 
In this paper, SENT specimens with a straight and slanted notch were tested in order to investigate the influence of the notch orientation on the ductile crack behaviour. The COD values obtained with the DIC method showed a significant $\mathrm{COD}_{\text {III }}$ component for the specimen with a notch of $31^{\circ}$, with the same order of magnitude as the $\mathrm{COD}_{\text {I }}$ component. Crack extension is determined by a combination of experimental potential drop measurements and numerical potential drop analysis. By combining the COD measurements with the crack extension measurements, it was apparent that mode I and mode III loading both have a different influence on the ductile crack extension. The influence of these modes on the ductile crack extension for notches under different angles will be investigated in further research. The results obtained from these tests will also be used to further improve the potential drop calibration procedure. Since the DIC system measured displacements at different heights on the specimen, it is possible to correlate measured CMOD values with COD values through trigonometric relationships. In other words, this paper is only a starting point in the process of developing a proper methodology to investigate and evaluate SENT specimens with a slanted notch.

\section{REFERENCES}

[1] D. B. Lillig, "The First ISOPE Strain-Based Design Symposium - A Review," in 18th International Offshore and Polar Engineering Conference, Vancouver, Canada, 2008, pp. 1-12.

[2] Ö. E. Güngör, M. Liebeherr, and D. Quidort, "Welding Evaluation of $21.6 \mathrm{~mm}$ X80 Linepipe Steel from Coil," presented at the 2nd South-East European IIW International Congress, Sofia, Bulgarije, 2010.

[3] M. Liebeherr, Ö. E. Güngor, D. Quidort, D. Lèbre, and N. Ilic, "Development and weldability assessment of heavy gauge X80 linepipe steel for spiral welded pipe," presented at the Cbmm welding of high strength pipeline steels international seminar, Araxa, Brazilië, 2011.

[4] L. E. Collins, D. Q. Bai, F. Hamad, and X. D. Chen, "High strength spiral linepipe for strain-based pipeline designs," in 17th International Offshore and Polar Engineering Conference, Lissabon, Portugal, 2007, pp. 2969-2975.

[5] A. Fonzo, "Full Scale Investigation on Strain Capacity on High Grade Large Diameter Pipes," 2011.

[6] F. M. Knoop, "Collapse Performance Of Hts (Helical seam Two Step) Welded Line Pipe," 2006.

[7] F. M. Knoop, "Mechanical Properties and Component behaviour of X80 Helical Seam Welded Large Diameter Pipes " 2008.

[8] X. Wang, "Validation of Strain Capacity Prediction Method - Comparison of Full-Scale Test Results to Predictions from Tearing Analysis Based on FEA " 2009.

[9] T. Zimmerman, "Buckling Resistance of Large Diameter Spiral Welded Linepipe " 2004.

[10] V. Pistone and G. Mannucci, Fracture arrest criteria for spiral welded pipes vol. 1: Elsevier Science B.V., 2004.

[11] F. M. Knoop and B. Sommer, "Manufacturing and use of spiral welded pipes for high pressure service - state of the art," in 5th International Pipeline Conference, Calgary, Canada 2004.

[12] M. Verstraete, W. D. Waele, K. V. Minnebruggen, R. M. Denys, and S. Hertelé, "Considerations in selecting laboratory scale test specimens for evaluation of fracture toughness," in 5th Sustainable Construction and Design Conference, Ghent, Belgium, 2013.

[13] S. Cravero and C. Ruggieri, "Correlation of fracture behavior in high pressure pipelines with axial flaws using constraint designed test specimens - Part I: Plane-strain analyses," Engineering Fracture Mechanics, vol. 72, pp. 1344-1360, Jun 2005.

[14] M. Liu, Y.-Y. Wang, and L. Collins, "Tensile strain capacity of spiral pipes," in 9th International Pipeline Conference, Calgary, Canada, 2012.

[15] D. P. Fairchild, M. L. Macia, S. Kibey, X. Wang, V. R. Krisham, F. Bardi, H. Tang, and W. Cheng, "A Multi-Tiered Procedure for Engineering Critical Assessment of Strain-Based Pipelines," in 21st International Offshore and Polar Engineering Conference, Maui, Hawaii, USA, 2011, pp. 698 - 705.

[16] American Petroleum Institute, "Specification for line pipe," ed. Washington, 2000.

[17] M. Verstraete, S. Hertelé, W. D. Waele, R. Denys, and K. V. Minnebruggen, "Measurement of ductile crack extension in Single Edge Notch Tensile specimens," in 15th International Conference on Experimental Mechanics, Porto, Portugal, 2012.

[18] M. A. James and J. C. Newman, "The effect of crack tunneling on crack growth: experiments and CTOA analyses," Engineering Fracture Mechanics, pp. 457-468, 2002. 